\title{
Biological and Ecological Features of Poecilancistrum Sp. Plerocercoid (Cestoda: Trypanorhyncha) Infection of Arabian Sea Meager Argyrosomus heinii (Steindachner, 1907)
}

Sarah Al Jufaili*, Vladimir Machkevskyi, Sami Al Sulaimi, Redha Bait Faraj and Nashwa Al Mazrooei

Fishery Quality Control Center Ministry of Fisheries Wealth, P.O. Box 427, P.C. 100, Muscat, Sultanate of Oman

\begin{abstract}
The Arabian Sea meager Argyrosomus heinii (Steindachner, 1907) is an endemic species of the family Sciaenidae, whose geographical distribution range is limited to the Sea of Oman and Arabian Sea. Despite the economic importance of Sciaenidae fishes in other parts of the world, the biology of $A$. heinii off the Sultanate of Oman is poorly understood and until now there are no publications on their parasites. The present study is the first report of the occurrence of helminthes parasitizing musculature of $A$. heinii, which were identified as plerocercoids of cestoda belonging to the genus Poecilancistrum Dollfus, 1929 (Trypanorhyncha Diesing, 1863). This study describes infection indices of these parasites, their biological and ecological variations, and distribution of the plerocercoid cysts in the musculature of $A$. heinii specimens. The study was carried out in the three regions of the Arabian Sea off Southern coasts of the Sultanate of Oman.
\end{abstract}

Keywords: Scianidae; Poecilancistrum; Arabian sea; First record

\section{Introduction}

Sciaenidae has a worldwide distribution and is one of the largest families of fishes with over 70 genera and up to 300 species [1]. These fish have high commercial importance in the tropical and subtropical waters around the world, where they usually are abundant in estuaries $[2,3]$. They are frequently infected with cestodes of the order Trypanoryncha Diesing, 1863 [4], which is a cosmopolitan group of marine cestodes [5]. Trypanoryncha comprises about 270 species [6]. These parasites are not dangerous to human health, but their presence in large numbers in the muscles reduces the commercial value of the fish [7-10] and sometimes leads to significant losses in the fishery industry. Obtaining information about parasite fauna of Omani fish and consequently the composition of harmful and pathogenic parasites, their distribution and seasonal variability of the their populations is very important to determine suitable strategies to regulate the fishery industry in the region. The subject of the present study is cestoda of the order Trypanoryncha parasitizing Arabian Sea meager Argyrosomus heinii (Steindachner, 1907), which is an important commercial species to the fishery industry in the Sultanate of Oman, with landings reaching up to $4913 \mathrm{Mt}$ in year 2011. In addition, Arabian Sea meager is an endemic species occurring only off the South-Eastern coasts of the Arabian Peninsula and the Sea of Oman (Indian Ocean). Despite the economic importance of $A$. heinii their biology is poorly studied [11], and their parasite fauna has not yet been investigated. Thus this study is the first report of the latter.

\section{Materials and Methods}

A total of 72 A. heinii were collected from December 2011 to June 2012 inclusive from the three localities off the South eastern coasts of the Arabian Sea: Al Sharqiya Governorate (Ras Madraka), Al Wusta Governorate (Lukbi) and Dhofar Governorate (Sharbatat) (Figure 1). The first sampling site for this study was Cape Sharbithat which is located off Dhofar Governorate (DHO) situated at $50-73 \mathrm{~m}$ isobaths. The second sampling area was Cape Souqarah off Al Wusta Governorate (WUS) near 37-53 m isobaths. Whereas the last sampling site was Cape Madrakah off Al Sharqiya Governorate (SHQ) which is located at isobaths between 7.3 and $11.4 \mathrm{~m}$. DHO and WUS stations are relatively close to each other with a distance of $64 \mathrm{~km}$ apart, while the last station SHQ is farthest away located $183 \mathrm{~km}$ Northeast of WUS (Figure 1).

The fish ranged between 33.7-73.2 cm long and 910-2664 g weight. Freshly caught fish were transported at $4^{\circ} \mathrm{C}$ to the Laboratory of Aquatic Parasitology of the Fishery Quality Control Center (FQCC) of the Ministry of Agriculture \& Fisheries of Oman, where were immediately examined. Total weight and lengths were measured to the nearest grams and centimeter respectively and sex of each fish was recorded. Body of each meager was divided into 6 sectors according

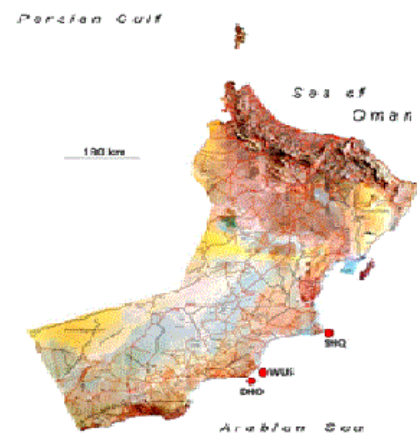

Figure 1: Areas of Arabian Sea meager's samplings.

*Corresponding author: Sarah Al Jufaili, Ministry of Agriculture and Fisheries Wealth, P.O. Box 427, P.C. 100, Al-Bustan-Muscat, Sultanate of Oman, Tel: +968 24743505; Fax: +968 24738222; E-mail: sjufaili@yahoo.com

Received February 03, 2014; Accepted March 26, 2014; Published April 10, 2014

Citation: Al Jufaili S, Machkevskyi V, Al Sulaimi S, Faraj RB, Al Mazrooei N (2014) Biological and Ecological Features of Poecilancistrum Sp. Plerocercoid (Cestoda: Trypanorhyncha) Infection of Arabian Sea Meager Argyrosomus heinii (Steindachner, 1907). J Aquac Res Development 5: 227 doi:10.4172/21559546.1000227

Copyright: ( $) 2014$ Al Jufaili S, et al. This is an open-access article distributed under the terms of the Creative Commons Attribution License, which permits unrestricted use, distribution, and reproduction in any medium, provided the original author and source are credited. 
Citation: Al Jufaili S, Machkevskyi V, Al Sulaimi S, Faraj RB, Al Mazrooei N (2014) Biological and Ecological Features of Poecilancistrum Sp. Plerocercoid (Cestoda: Trypanorhyncha) Infection of Arabian Sea Meager Argyrosomus heinii (Steindachner, 1907). J Aquac Res Development 5: 227 doi:10.4172/2155-9546.1000227

Page 2 of 7

to the diagram (Figure 2). Skeletal muscles of each section with the skin was separated from the bones, filleted, weighed and examined for trypanorhynch larvae cysts on candling tables. All cysts found were removed from the musculature, measured, their localizations were recorded, and then they were dissected using fine dissecting needles in a drop of physiological saline. Encysted larvae were transferred to small glass petri dish (50 $\mathrm{mm}$ diameter) with physiological saline to relax the cestode and aid in release of their bothria. The worms collected were gently pressed between cover slip and glass slide and fixed using AFA (Acetic acid-Formalin-Alcohol) solution. Some of the cestodes were stained with Mayer's paracarmine [12], the others were stained with acetocarmine (Russian modification) [13], dehydrated using an ethanol series (80-100\%) and mounted in Canada balsam.

Parasitological terms and infection indices are used according to Bush et al. [14] Data analysis was carried out using the descriptive statistics (mean and standard error), Mann-Whitney U-test, Pearson correlations and Fisher LSD test. All a statistics and their graphical representation were produced using the software package Statistica 6 for Windows.

\section{Results}

Larvae of Poecilancistrum sp. (Figure 3) were found in all fish samples collected in three regions, but with different value of infection indices (Table 1).

\section{Geographical factor}

It has been established that the infection of the Arabian Sea meager by Poecilancistrum sp. plerocercoids is uneven in each of the three areas (Table 1).

Fishes from Al Wusta Governorate had the highest invasion value

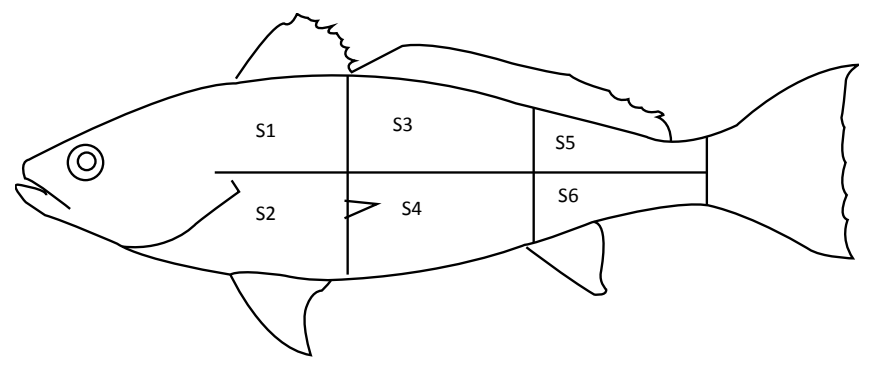

Figure 2: The scheme of body regions of $A$. heinii.

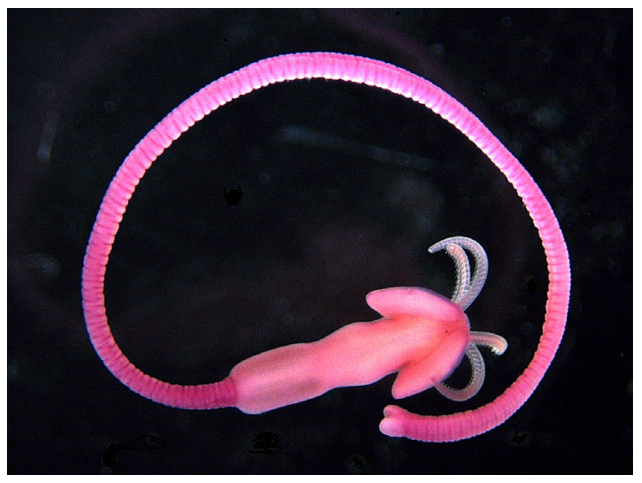

Figure 3: Excysted Poecilancistrum sp. plerocercoid (Trypanhorhyncha) from A. heinii (original, x 12,5, stained with acetic-acid carmine).

\begin{tabular}{|c|c|c|c|c|c|c|c|}
\hline \multirow[t]{2}{*}{ Location } & \multirow[t]{2}{*}{$\mathbf{N}$} & \multirow[t]{2}{*}{ Preva-lence } & \multirow{2}{*}{$\begin{array}{l}\text { Mean } \\
\text { intensity } \\
\pm \text { SE } \\
\text { (spm. } \\
\text { per fish) }\end{array}$} & \multirow{2}{*}{$\begin{array}{l}\text { Abundance } \\
\pm \text { SE } \\
\text { (spm. per } \\
\text { fish) }\end{array}$} & \multicolumn{3}{|c|}{ Mann-Whitney U-test } \\
\hline & & & & & $\begin{array}{l}\text { DHO* } \\
\text { vs. WUS }\end{array}$ & $\begin{array}{l}\text { DHO vs. } \\
\text { SHQ }\end{array}$ & $\begin{array}{l}\text { WUS } \\
\text { vs. SHQ }\end{array}$ \\
\hline $\mathrm{DHO}^{*}$ & 53 & 78 & $\begin{array}{l}4,32 \pm \\
0,51\end{array}$ & $3,34 \pm 0,46$ & $175^{\star *}$ & & \\
\hline WUS & 15 & 93 & $\begin{array}{l}8,14 \pm \\
1,1\end{array}$ & $7,60 \pm 1,16$ & & 79 & \\
\hline $\mathrm{SHQ}$ & 4 & 50 & $\begin{array}{l}4,00 \pm \\
2,00\end{array}$ & $2,00 \pm 1,41$ & & & 8 \\
\hline
\end{tabular}

*abbreviations of region see in Material and Methods ${ }^{* *}$ Bold values U-test for significant differences at $p \leq 0,05$.

Table 1: Infection indices of Poecilancistrum sp. ex Arabian Sea meager from the three regions of the Arabian Sea off Oman.

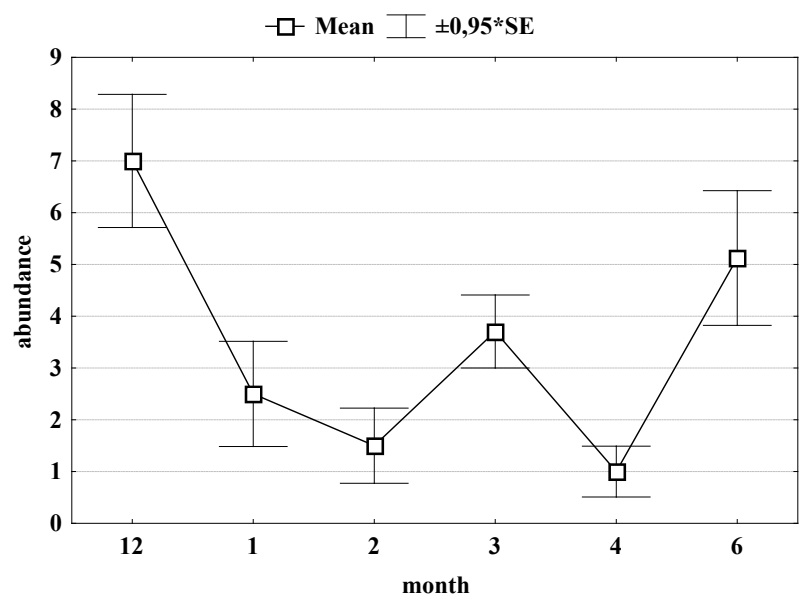

Figure 4: Seasonal dynamics of an abundance index of Poecilancistrum sp. plerocercoids (spm. per host) in the $A$. heinii at the DHO Governorate.

with prevalence exceeding $90 \%$ and intensity of almost 7.6 spm. per host. The lowest infection rate of plerocercoids in the musculature of Arabian Sea meager was from Al Sharqiya Governorate, were the prevalence was almost 2 -folds lower than the other areas and with an intensity of more than 3.5 times lower than that of $\mathrm{Al}$ Wusta Governorate.

Interestingly fishes from Dhofar Governorate showed an intermediate infection rate compared to the other sampled sites, prevalence and intensity of infection in this area exceeded those of Al Sharqiya Governorate by 1.56 and 1.67 times, respectively. But compared to the intensity of the croaker infection in Al Wusta Governorate, plecrocercoid infection rates in Dhofar Governorate was 2.3 times lower and the intensity of infection was less than 1.2 times.

\section{Seasonal factor}

The results of seasonal changes in the invasion parameters of the infection of Arabian Sea meager was obtained from data of fish samples from DHO Governorate only as shown in Figure 4, where it is the only location with samples obtained during the complete period of the study. It was established that the maximum number of the plerocercoids infrapopulation in population of the A. heinii took place in the first half of the NE Monsoon season during December. Then, in January, where the weather becomes cooler, the infection rate decreased by 3 -folds and reached its lowest point during February which is also the second half of the NW Monsoon season. In March, the last month of the NE Monsoon, the level of infection of the Arabian Sea meager by trypanorhynch larvae increased slightly, but unexpectedly fell to its 
Citation: Al Jufaili S, Machkevskyi V, Al Sulaimi S, Faraj RB, Al Mazrooei N (2014) Biological and Ecological Features of Poecilancistrum Sp. Plerocercoid (Cestoda: Trypanorhyncha) Infection of Arabian Sea Meager Argyrosomus heinii (Steindachner, 1907). J Aquac Res Development 5: 227 doi:10.4172/2155-9546.1000227

lowest level in April the first month after Inter-Monsoon rest. With the onset of the SW Monsoon in June, the number of these parasites increased five times their minimum number in April. Not all points on our chart (Figure 4) are reliably distinguished from each other, but it is clear that there is a trend of an increase in the number of plerocercoids in relation to an increase in water temperature and water productivity during the summer months of the SW Monsoon [15-17]. Most likely, the increase in the productivity of the sea has a positive impact on the number of infrapopulations of Poecilancistrum sp. cestode in the first intermediate host, situated on one of the initial stages of the food chain of the marine ecosystem.

\section{Meager sex factor}

Prevalence of infection of males was slightly higher than that of females, however the difference is negligible (Table 2).

\section{Meager size factor}

In order to investigate the distribution of plerocercoids in the total sample of Arabian Sea meager, the samples were divided into 4 size groups $(31-40 \mathrm{~cm}, 41-50 \mathrm{~cm}, 51-60 \mathrm{~cm}$ and $61-70 \mathrm{~cm})$. It is revealed that the rate of infection is dependent from size (Figure 5).

\section{Meager condition factor}

As a part of the host-parasite relationship we investigated the effect of plerocercoids on host, by using the Fulton criterion of fish nutrition: the ratio of the total weight of fish to its maximum length [18]. The relationship between host condition (fatness) and parasite infection rate is shown in Figure 6.

\begin{tabular}{|l|l|l|l|l|l|}
\hline Sex & N & Preva-lence & $\begin{array}{l}\text { Mean intensity } \\
\pm \text { SE (spm. per } \\
\text { fish) }\end{array}$ & $\begin{array}{l}\text { Abundance } \\
\mathbf{I S E} \text { (spm. per } \\
\text { fish) }\end{array}$ & $\begin{array}{l}\text { Mann-Whitney } \\
\text { U-test }\end{array}$ \\
\hline female & 32 & 80 & $4,56 \pm 0,67$ & $3,56 \pm 0,62$ & $\begin{array}{l}\text { Female vs. } \\
\text { male }\end{array}$ \\
\hline male & 18 & 87 & $4,13 \pm 0,8$ & $3,44 \pm 0,78$ & \\
\hline juvenile & 3 & 33 & 1 & $0,33 \pm 0,33$ & \\
\hline
\end{tabular}

Table 2: Dependence of infection indices of Poecilancistrum sp. plerocercoids on sex and maturity of $A$. heinii in the DHO Governorate.

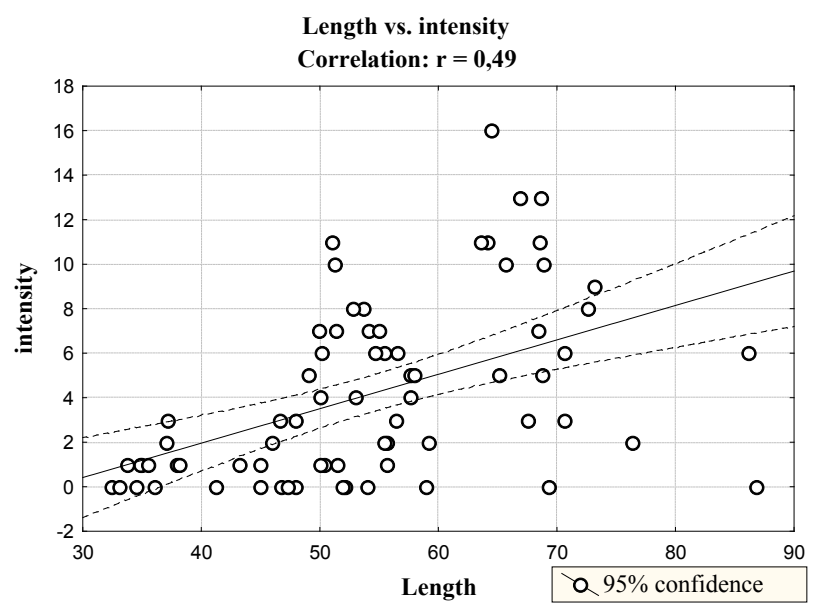

Figure 5: The dependence of the invasion of Arabian Sea meager with Poecilancistrum sp. plerocercoids of its length.

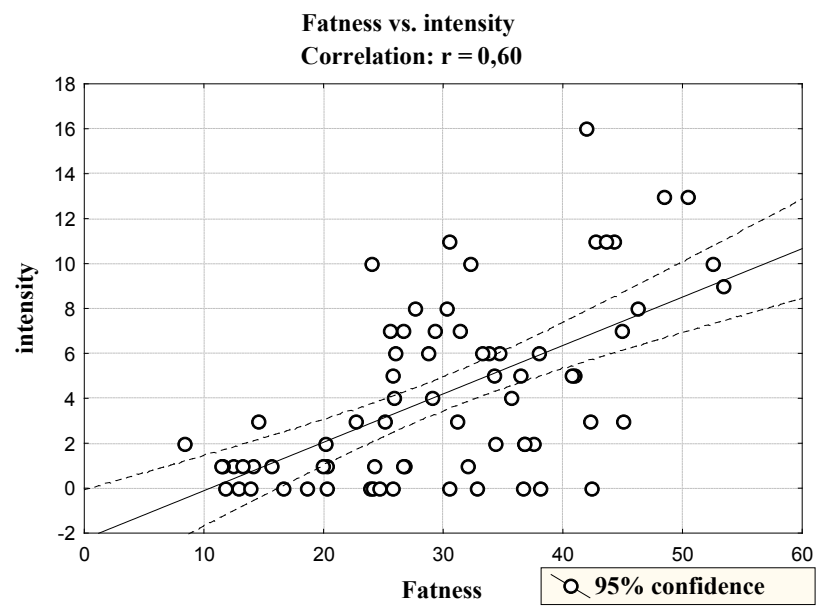

Figure 6: Dependence of the level of infection of Arabian Sea meager by Poecilancistrum sp. plerocercoids on its condition (fatness).

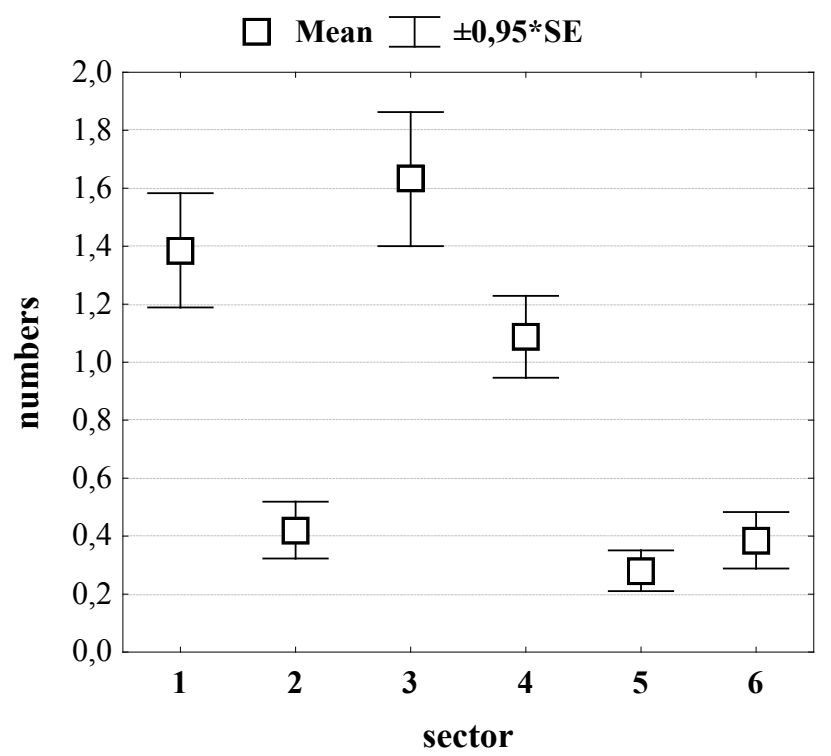

Figure 7: Distribution of plerocercoids in different sectors of the body of Arabian Sea meager (mean values with errors).

\section{Distribution of plerocercoids in the different body parts of host}

Six sectors were provisionally allocated in the body of the host as shown in Figure 2, which was done by drawing a horizontal line along the midline of the body and a vertical one from head to tail, about the same distance from each other. According to the shape of the Arabian meager, the six body sectors that were allocated had different weight and anatomical features. In order to understand whether or not this could affect the parasites concentration, the size of their ecological niche (muscle mass) was defined for each area. It was decided to evaluate not only the average number of plerocercoids in each sector of the fish body, but also to include the average number of parasites per unit weight of each sector.

As a result we have established that the plerocercoids are unevenly distributed in the body of Arabian Sea meager and that this unevenness is stable in nature (Figure 7 and Table 3). 


\begin{tabular}{|l|l|l|l|l|l|}
\hline Sector & $\mathbf{1}$ & $\mathbf{2}$ & $\mathbf{3}$ & $\mathbf{4}$ & $\mathbf{5}$ \\
\hline 2 & $0,0005^{\star}$ & & & & \\
\hline 3 & 0,09 & 0,000000 & & & \\
\hline 4 & 0,67 & 0,00009 & 0,21 & & \\
\hline 5 & 0,00001 & 0,34 & 0,000000 & 0,000001 & \\
\hline 6 & 0,00003 & 0,51 & 0,000000 & 0,000005 & 0,78 \\
\hline
\end{tabular}

${ }^{*}$ marked differences are significant at probability value $\leq 0,05$

Table 3: Probabilities for Fisher LSD test of the distribution of Poecilancistrum sp. plerocercoids over body sectors (ratio of specimens in each sector of the total number per fish).

\section{Discussion}

Cestodes belonging to the order Trypanorhyncha, are mostly parasites of marine animals, they usually exhibit a complex three hosts life cycles. The first intermediate hosts for these cestodes are crustaceans, the second intermediate hosts are demersal fishes while definitive hosts are usually cartilaginous fish [9]. By linking the dynamics of infrapopulation [14] of Poecilancistrum sp. plerocercoids and consequently, the degree of parasites infestation of $A$. heinii with different environmental parameters, it is possible to understand how these parameters can affect the processes of the Poecilancistrum sp. life cycle and, ultimately the size and the spatial and temporal structure of its population. Population structure of the Poecilancistrum sp. can be categorized into three main infrapopulation: procercoid, plerocercoid and adult cestode. Since the plerocercoids infrapopulation is found in Arabian Sea meager, which is also the second intermediate host for Poecilancistrum $s p$. it is safe to assume that the procercoids infrapopulation is localized in the first intermediate host the crustaceans and invertebrate population which are the main food objects for the majority of Sciaenidae [19]. Knowing that the definitive host of Trypanorhyncha cestodes are elasmobranches [7,9] it is possible to assume that they are the hosts for Poecilancistrum sp. mature cestodes infrapopulation. Provided that the structure of the bottom crustaceans community is relatively stable in time and space then the factors determining the variability of infection level in the Arabian Sea meager are the definitive hosts of Poecilancistrum sp. which are rays and sharks, because these predators perform a dual function in the life cycle of Poecilancistrum sp. by replenishing the population of mature cestode within them through feeding on second intermediate host and the subsequent reinfection of first intermediate host by releasing of eggs from mature worms into their habitats.

\section{Geographical factor}

Based on numerous studies showing that geographic isolation of aquatic organisms and the resulting differences in ecological conditions in many cases are an effective factor that may influence the parasite invasion process in ecosystems.

These results could be explained by comparing the differences in the depth of each study area. The shallowest station among the selected areas was SHQ, while WUS and DHO station had almost similar depths. In order to further understand the cause of these differences, we need to understand the distribution of the first intermediate (mollusks, crustacean) and the definitive (cartilaginous fish) hosts of Poecilancistrum sp., however the biology of cartilaginous fish that inhabit the Arabian Sea and Oman, are not well understood. From the limited sources that were available $[20,21]$ it has been found that the distribution of the majority of sharks and rays in Oman is not strictly limited to certain depths and distances from shore. Thus, the sharks and rays have the same probability to be infected and release eggs of mature cestode to the environment. These eggs can become a source of infection for the first intermediate hosts which could be any crustacean ranging from $10-100 \mathrm{~mm}$ in size, this could include different mollusks, shrimp, crabs, isopods species. While N.E. Mattis [22] indicated that the first intermediate hosts of the cestode Poecilancistrum cariofillum [9] Dollfus, 1929 are the planktonic crustaceans Acartia tonsa, Tigriopus californianus and Pseudodiaptomus sp. we believe that on the coast of Oman it should be larger crustaceans with a size more suitable for the diet of croaker which can reach a length of $90 \mathrm{~cm}$. it is noteworthy that Mattis [22] has identified the above mentioned crustaceans as hosts procercoid $P$. caryophyllum through experiment. If such invasion really existed in nature, it would have been probably a dead end, as it is difficult to imagine how a medium-sized croaker could eat crustaceans about a millimeter in length and consequently acquires numerous plerocercoids. Besides, Acartia tonsa lives in the surface layers of the sea which is not the habitat of A. heinii. Various researchers have successfully infected planktonic crustaceans in the laboratory [23], but none of them could prove that the same process actually happens in the "wild " samples of planktonic crustaceans. The most likely explanation for the uneven infection of Arabian Sea meager with Poecilancistrum $s p$. plerocercoids in different areas along the coast of Oman lies in the peculiarities of the spatial distribution of mollusks and crustaceans infected with procercoids of Poecilancistrum sp. [24].

\section{Seasonality factor}

One of the rules of Ecological Parasitology [25] states that the population of the parasite is always in direct proportion to the number of its hosts. It is therefore logical to assume that the increase of crustaceans during summer must necessarily lead to an increase in the level of infestation of Arabian Sea meager with trypanorhynch plerocercoids. So even with the absence of monthly data, seasonal variability of $A$. heinii infection by plerocercoids can be modeled as follows: summer season accelerates the level of invasion, which probably begins in June along with increased productivity, it may continue throughout the period of SW Monsoon, including autumn transition period until December which is the early NE Monsoon. As the temperature and the productivity of coastal waters decreases, the infection rate Arabian Sea meager with Poecilancistrum sp. plerocercoids is also reduced.

\section{Meager sex factor}

The comparison of infection parameters of male and female Arabian Sea meager has shown that host sex is not a determinant factor in differences of infection parameters. Lack of sexual distinctions in infection with this parasite can testify that males and females of Arabian Sea meager don't conduct a separate way of life during any periods of sexual cycle when reaching sexual maturity as it is characteristic for some fishes (Gobiidae, Salmonidae) [26,27]. For example, females of Gobiidae fishes Neogobius fluviatilis and Neogobius syrman, having suspended fully developed gonads, leave the coastal zone, and males remain to protect and care for the eggs. The most characteristic marker of such spawning behavior of $N$. fluviatilis and N. syrman is the myxozoan parasite Kudoa quadratum which has been observed that within a very short time, intensity of infection of males hosts with this parasite increased thousands times unlike the females who have left their spawning grounds [27]. Another example is the Pacific salmon Oncorhynchus nerka with feeding divergence of males and females observed before the spawning period that testifies their separate way of life. This regularity was revealed by means of a biological tag by plerocercoids of the cestoda Diphyllobothrium sp. [26].

\section{Meager size factor}

Size is an important factor, which in the first place, may indicate age 
of the host. It could be visualized that plerocercoids living in the body of their intermediate host can retain the ability to infect the final host (sharks and rays) for many months as it is known for other parasites $[25,26]$ which could explain the increase of their accumulative numbers as the fish grows. Thus, the longer fish lives the higher the numbers of parasites it has. However, we do not have enough data in our material to prove whether there is a true relation between fish size and their age. Thus, we could explain this observation by speculating that the bigger the fish, the larger the amount of food they consume (which in this case are the first intermediate hosts) leading to an increase in numbers of cestode plerocercoids in their muscles.

\section{Meager condition factor}

The comparative analysis revealed statistically significant direct relationship invasion level of $A$. heinii with parasites and its body condition. From this we can conclude that parasites have a positive "impact" on its host. The more parasites, the higher the nutritional state of their host. In parasitology, there are many other examples where the infection of some parasite causes host gigantism [28,29]. However, a more realistic explanation is that most likely there is a minimal negative impact of the plerocercoids on the host, as they will inevitably consume the resources of its host for its own growth and development. It has been revealed as a natural law that there is an intrapopulation genetic differentiation that renders some individual to be more successful than other in the employment of food resources, which could result in different feeding activity. Therefore, the more active the fish are, the more it will feed, which could explain why larger hosts had the highest numbers of cestode plerocercoids. A similar feature was noted above in the comparison of infection of the meager's different size groups.

\section{Distribution of plerocercoids in the different body parts of host}

In average the majority of the parasites accumulation was observed in sectors number $1,2,3,4$, and their highest numbers were in sectors № 1,3 , 4. of these, the maximum number of plerocercoids were from the sector number 3 (Figure 2). Looking at the vertical zone, the dorsal sectors total was 1.8 times more infected with cestodes larvae, in these sectors $64 \%$ of plerocercoids were found compared to $36 \%$ in the ventral sectors. We have grouped the sectors in pairs and tried to estimate the horizontal distribution of the parasites from head to tail. It turned out that most of the plerocercoids were concentrated in the central sectors of the fish body (№ 3, 4), with a concentration of $52.6 \%$ of the total population of parasites. While the area around the head (№ $1,2)$ comes second with $35.1 \%$ concentration. The least concentration was observed in the tail with $12.4 \%$ concentration (Figures 2 and 7).

We hypothesized that the factors affecting the distribution of plerocercoids in the Arabian Sea meager body is the size of the ecological niche, i.e. the muscle mass of each of the selected sectors of the fish. In order to confirm or refute this, we dissected and weighed the mass of each of the sectors and determined their relative (\%) contribution to the total muscle mass (Figure 2). It has been found that the vertical muscle mass was equally distributed: the dorsal part had $51.5 \%$ composition and the abdominal part was composed of $48.5 \%$. At the same time, the muscles mass was unevenly distributed along the back (Figure 2). Most of it (44\%) was concentrated in the anterior end (sectors № 1,2), the middle of the muscle mass was slightly less $(41 \%)$ (sectors № 3, 4), and the least (15\%) was in the tail (sectors № 5, 6).

By following this logic it is possible to tell that the direct dependence between the average quantity of parasites and the size of muscular weight of each sector is not revealed. Most of the parasites are found in the middle of the body, which is not the most massive sector of the body mass. We decided to calculate the parasite density per unit of muscle mass for each sector. We found that the maximum concentration of plerocercoids ( $28.2 \%$ of total) occurred in sector number 3 . The second highest concentration was in the dorsal sectors after the head (sector № 1) (19.3\%). Next in descending order, was sector number 4 which is consisting of muscles separating the abdominal cavity and skeletal muscles with a parasite concentration $(16,6 \%)$. The same PD of (16, $6 \%$ ) was in the lower tail (sector number 6), which shares a border with sector number 4. In the dorsal part of the caudal peduncle (sector № 5) the PD was equal to $11.9 \%$. Finally, the lowest concentration was recorded in the area mainly consisting of the abdominal muscles (sector № 2) with a PD of (7.3\%). This sector is bordering the largest part of the abdominal cavity and is in immediate proximity to the digestive tract [30-34].

Accumulation of parasites in the muscles may depend on several factors: the intentional dispersal behavior of the parasite or the anatomical features of the host to facilitate their movement to specific places. First, we considered the likely dependence of PD on the anatomical features of fish. An infection of the Arabian Sea meager with trypanhorhyncha larvae occurs when they eat the first intermediate host which is benthic mollusks and demersal crustaceans. The larvae are released from the tissues of the first intermediate host and travel to the stomach and front part of the intestine, it may then penetrate into the blood system. One of the common speculations has it that these procercoids penetrate the host blood vessels and are passively carried by blood through the host body till they are stuck in the smallest vessels [25]. The alimentary tract and abdominal cavity of the fish contains numerous large and small blood vessels [30], which could ensure a successful transfer of the parasites in the host organism. This could explain why parasites were found in sectors that are localized near major plexus of blood vessels. However, we cannot confirm in this case that sector № 3 is better supplied with blood than other sectors, even though the average amount and concentration of the plerocercoids in it was the highest. At the same stage, the sector number 2 which is located closest to the front of the digestive tract and to the largest number of blood vessels [30], had the lowest parasites concentration $(7.3 \%)$ (Figure 7). From this it can be assumed that the dispersed plerocercoids in the meager body are not passive but could has some possible taxis. This allows the parasite to settle relatively evenly and to occupy sectors of the caudal peduncle, providing the same parasite concentration in sectors number 6 and number 4 , although sector number 4 is 2.5 times larger. Therefore, there could be assumed that the even placement of the plerocercoids in their host is part of parasite adaptation to reduce the load on their host and thus creating a balanced relations in the hostparasite systems.

The obtained information on the distribution of Poecilancistrum sp. plerocercoids can have practical value. The results can be used for rapid analysis of Arabian Sea meager in processing companies. They could easily examine the parasite by sampling a tissue sample taken from sector number 3, which is the most infected part of the host body. Also, since these worms are known to infect sharks and rays as definitive hosts, it important to note that these larvae are not associated with human safety or any health hazards, if they ever got in the human digestive tract they will normally be digested without any negative consequences. Thus, by analyzing the data obtained from this study and knowing that it is impossible to influence or control the infection in open waters, we could establish an idea about the infection site preference of these parasites $A$. heinii (frequency of occurrence and intensity of infection) 
Citation: Al Jufaili S, Machkevskyi V, Al Sulaimi S, Faraj RB, Al Mazrooei N (2014) Biological and Ecological Features of Poecilancistrum Sp. Plerocercoid (Cestoda: Trypanorhyncha) Infection of Arabian Sea Meager Argyrosomus heinii (Steindachner, 1907). J Aquac Res Development 5: 227 doi:10.4172/2155-9546.1000227

Page 6 of 7

we could either educated the fish processing companies to change their processing methods in order to get more value from the infected fish, or to establish some regulations about fishing grounds which are reported to have less infection intensities or to observe seasons in which the fish are less infected.

\section{Conclusion}

Studies on marine cestode of the Omani coasts of Sea of Oman and Arabian Sea are poorly recognized, so far this study is the first in the region and it represents the most comprehensive investigation on Trypanorhyncha cestode infecting Sciaenidae giving new host and locality records of the investigated parasite. Also, results obtained from this study provides baseline information about the parasite fauna of an important endemic fish species in the country, adding new data about the population dynamics and geographical distribution of this parasite, while giving an insight on the infection features of this parasite on this host. Moreover, by comparison of infection parameters along the different sampling sites, interesting data on the uneven geographical distribution and seasonal changes in the infection levels of this parasite were also obtained. Features of host-parasite relationships between the Arabian Sea meager and plerocercoids Poecilancistrum sp., which were reflected in the uneven distribution of the parasite in the host muscles were also revealed.

Besides its scientific novelty this work has a practical value, because there is an aesthetic aspect in the utilization of the fish that is infected by plerocercoids Poecilancistrum sp. Plerocercoids are large in size and their color is easily distinguishable against the color of fish meat. This can lead to consumer complaint, lower marketing price and removal of the caught fish from the market leading to economic losses. From the information obtained during this study and since it is not possible to influence the process of the infection in Arabian Sea meager we can educate the fishermen about the existence of the phenomenon and indicate the regions and seasons where the infection of fish is the least. In addition, to aid in the rapid analysis of catches of $A$. heiini for this infection, tissue samples must be taken at the most infected parts of its body. This parasite is not dangerous to humans and does not affect the taste quality of the fish, so in the case of a high infection levels it can be recommend to process as other fish products.

\section{Acknowledgement}

The authors are very grateful to the Ministry of Agriculture and Fisheries Wealth, of the Sultanate of Oman for the financial support for this investigation. We would like to extend our thanks to Head of inspection department at the FQCC Khamis Al Falahi and inspector Khamis Al Araimi for their assistance in collecting the samples. Also, to Captain Hamdan Al Waheibi for his valuable information on the occurrence of the Arabian Sea meager in the investigated areas. We would also like to thank PhD E.V. Dimitrieva (IBSS) for her valuable revision to this manuscript.

\section{Conflict of Interests}

We (Laboratory of Aquatic Parasitology) are a public government laboratory, belonging to Ministry of Agriculture and Fisheries Wealth, Fishery Quality contro Center, certify that there is no conflict of interest with any financial organization regarding the material discussed in the manuscript.

\section{References}

1. Vinson C, Gomes G, Schneider H, Sampaio I (2004) Sciaenidae Fish of the Caeté River Estuary, Northen Brasil: Mitochondrial DNA Suggests Explosive Radiation for the Western Atlantic Assemblage. Genetic and Molecular Biology 27: $174-180$

2. Druzhinin AD (1971) The Distribution of Lutjanidae and Sciaenidae (Pisces) in the Indian Ocean. Indian Journal of Fisheries 18: 52-66.

3. Waessle JA, Lasta CA, Favero M (2003) Otholit Morphology and Body Size
Relationships for Juvenile Sciaenidae in The Río De La Plata Eustary (35$36^{\circ}$ S). Sci. Mar 67: 233-240.

4. Overstreet RM (1977) Poecilancistrum Caryphyllum and Other Trypanorhynch Cestode Plerocercoids from the Musculature of Cynoscion Nebulosus and Other Scianidae Fishes in the Gulf of Mexico. The Journal of Parasitology. 63: 780-789.

5. Ibrahim MM (2000) Histopathological of Trypanorhyncha Plerocercoids (Cestodes) in Marine Fish from Waters of the Arabian Gulf. J KAU: Mar. Sci. 11: $59-73$

6. Haseli M, Malek M, Palm HW (2010) Trypanhorhynch Cestodes of Elasmobranchs from Persian Gulf. Zootaxa, 2492: 28-48.

7. Palm HW, Moller H, Petersen F (1993) Otobothrium Penetrans (Cestoda; Trypanorhyncha) in the Flesh of Belonid Fish from Philippine Waters. International Journal of Parasitology. $23: 749-755$.

8. Palm HW (1997) Trypanorhynch Cestodes of Commercial Fishes from Northeast Brazilian Coastal Waters. Mem. Inst.Oswaldo Cruz, Rio De Janeiro 92: 69-79.

9. Palm HW (2004) The Trypanorhyncha Diesing, 1863. Bogor: PKSPL-IPB Press. 11-710.

10. Hassan MA, Palm HW, Mahmoud MA, Jama FA (2002) Trypanorhynch Cestode from the Musculature of Commercial Fishes from the Arabian Gulf. Arab Journal of Scientific Research. 20: 74-86.

11. Randall JE (1995) Coastal Fishes of Oman. Crawford House Publishing Pty Ltd Bathurst, Australia. 439.

12. Salgado-Maldonado G, Pineda-López RF (2003) The Asian Fish Bothriocephalus Acheilognathi: A Potential Threat to Native Freshwater Fish Species in Mexico. Biological Invasions 5: 261-268.

13. Machkevskyi VK, Dmitrieva EV, Al-Jufaili S, Al-Mazrooei NAM (2013) Microcotyle Omanae N. Sp. (Monogenea: Microcotylidae), A Parasite of Cheimerius Nufar (Valenciennes) (Sparidae) from the Arabian Sea. Syst Parasitol 86: 153-163.

14. Bush AO, Lafferty KD, Lotz JM, Shostak AW (1997) Parasitology Meets Ecology on its Own Terms: Margolis et al. Revisited. Journal of Parasitology 83: $575-583$

15. Kochergin AT, Ganichev PA (1998) Features Annual Dynamics of Upwellings of the North-Western Indian Ocean. Proceedings of the Southern Research Scientific Institute of Marine Fisheries \& Oceanography 44: 206-209.

16. Al-Marzuqi (2011) ASM Biology, Stock Assessment and Fishery Management of the Santer Seabream Cheimerius Nufar (Val., 1830) from the Arabian Sea of Oman. Ministry of Agriculture and Fisheries Wealth. 1-112.

17. Piontkovski S, Al-Azri A, Al-Hashmi K (2011) Seasonal and Interannual Variability of Chlorophyll-A in The Gulf of Oman Compared to the Open Arabian Sea Regions. International Journal of Remote Sensing 32: 7703-7715.

18. Fulton T (1902) Rate of Growth of Sea Fish. Fish. Scotl. Sci. Invest. Report, 20: 226- 334 .

19. Svetovidov AN (1964) Fishes of Black Sea. L. Nauka 551

20. Al-Abdessalaam TH (1995) ZS Marine Species of the Sultanate of Oman Ministry of Agriculture and Fisheries Wealth. 283-285.

21. Henderson AC, Al-Oufi H, Mcllwain JL (2008) Survey, Status \& Utilization of the Elasmobranch Fisheries Resources of the Sultanate of Oman. Sultan Qaboos University, Agriculture and Fisheries Development Fund. 5-136.

22. Mattis NE (1986) The Development of Two Tetrarhynchidean Cestodes from the Northern Gulf of Mexico. Ph.D Thesis, University Southern Mississipi 171.

23. Solonchenko Al (1982) Helminth Fauna of Fishes in Azov Sea. Kiev: Naukova Dumka 152

24. Vijayalakshimi C, Vijayalakshimi J, Gangadharam T (1996) Some Trypanhorhynchid Cestodes from the Shark Scoliodon Palasorrah with the Description of a New Sp. Tentacilaria Scoliodoni. Rivista Di Parassitologia XIII (LVII) (N 1) 83-88.

25. Dogiel VA (1962) General Parasitology. Leningrad 5- 463 
Citation: Al Jufaili S, Machkevskyi V, Al Sulaimi S, Faraj RB, Al Mazrooei N (2014) Biological and Ecological Features of Poecilancistrum Sp. Plerocercoid (Cestoda: Trypanorhyncha) Infection of Arabian Sea Meager Argyrosomus heinii (Steindachner, 1907). J Aquac Res Development 5: 227 doi:10.4172/2155-9546.1000227

26. Konovalov SM (1980) Population Biology of the Pacific Salmons. "Science" Leningrad Office, Leningrad. 1-237.

27. Naydenova NN (1974) Parasite Fauna of Fish of the Family Gobiidae of the Black and Azov Seas. Naukova Dumka, Kiev 10-182.

28. Ginetsinskaya TA (1968) Trematodes, Their Life Cycles, Biology and Evolution. Acad Nauka, Leningrad. 5-411.

29. Arnott SA, Barber I, Huntingford FA (2000) Parasite-Associated Growth Enhancement in a Fish-Cestode System. Proc. R. Soc. Lond. B 267: 657-663.

30. Pravdin IF (1966) Guide to the Study of Fish. Pishchepromizdat. 376.
31. Al-Zubaidy AB (2006) First Records in Yemen of Two Larval Trypanorhynch Cestode in Commercial Fish (Lerthrinus Lentjan) from the Red Sea. JKAU:Mar. Sci. 17: 79-87.

32. Al-Zubaidy AB, Muhaisen FT (2011) Larval Tapeworms (Cestode: Trypanorhyncha) from Some Red Sea Fishes, Yemen. Mesopot. J Mar Sci 26 : $1-14$.

33. Dogiel VA (1959) Invertebrate Zoology. Acad. Soviet Science, M 5-511.

34. Navigation Map: Arabia-South-East Coast // @Crown Copyright, 13 January 1984 (1984). 